\title{
Laminate veneer ceramics in aesthetic rehabilitation of teeth with fluorosis: a 10-year follow-up study
}

\author{
Zeynep Basagaoglu Demirekin * (10) and Suha Turkaslan (1)
}

\begin{abstract}
Background: Fluorosis is one of the color anomalies seen in teeth. White lines and blurred areas associated with mild fluorosis are barely noticeable; in its severe form, tooth enamel surface changes ranging from staining and pitting may be observed. The treatment of fluorosis not only provides aesthetic and functional correction but also helps to improve the patient's self-esteem.

Methods: The present retrospective study evaluated the clinical quality, success rate, and estimated survival of porcelain laminate veneers in teeth with anterior fluorosis. Three hundred fifty-eight porcelain laminate veneers (254 in the anterior maxilla and 104 in the mandible) were "functional" restorations that covered the incisal edge and part of the palatal/lingual side of the tooth with a $1 \mathrm{~mm}$ high palatal bevel. Ceramic veneers were fabricated with lithium disilicate reinforced glass-ceramic material (IPS e.max Press, Ivoclar Vivadent, Schaan, Liechtenstein). The modified United States Public Health Service criteria were used for clinical evaluation of the restorations.
\end{abstract}

Results: On the basis of these criteria, marginal adaptation, color match, marginal discoloration, surface roughness, restoration fracture, tooth fracture, restoration wear, antagonist tooth wear, caries and postoperative sensitivity were evaluated yearly. The survival rate in the current study was $\geq 0.997$ for 10 years.

Conclusions: The results of this clinical study should encourage clinicians to consider ceramic veneers over crown restorations when restoring the smile of patients with advanced fluorosis.

Keywords: Fluorosis, Laminate veneer ceramics, Aesthetic rehabilitation

\section{Background}

Smiling is known to benefit general human health by increasing happiness along with the secretion of endorphins, reducing stress and blood pressure [1]. Smiling relies on essential components such as the color and proportion of the teeth, structure of the gingival tissue, and the lip frame [2]. An unpleasant smile can affect the patient's self-esteem. A frequently encountered complaint is the change of tooth color, which is one of the

*Correspondence: dtzeynepbasagaoglu@yahoo.com.tr Department of Prosthodontics, Suleyman Demirel University Faculty of Dentistry, Isparta, Turkey most critical components of the ideal smile. Fluorosis is one of the color anomalies seen in teeth. It is a developmental disorder of the enamel that affects ameloblasts at the mineralization stage due to systemic fluoride intake that is greater than the optimal of $1 \mathrm{ppm} /$ day $[3,4]$.

The outer layer of enamel tissue that is exposed to the bacterial flora is characterized as hypermineralized and acid-resistant. On the other hand, the subsurface layer is more porous and has homogeneously distributed hypomineralization areas $[5,6]$. White lines and blurred areas associated with mild fluorosis are barely noticeable; in its severe form, tooth enamel surface changes ranging from staining and pitting may be observed $[5,7,8]$. 
The treatment of fluorosis not only provides aesthetic and functional correction but also helps to improve the patient's self-esteem $[9,10]$.

In cases of generalized dental fluorosis with surface defects, aesthetic, phonetic, and functional rehabilitation requires the removal of unsupported and pitted enamel or dentin tissue (with or without the occlusal vertical dimension) and fabrication of crowns or ceramic veneers [11]. Porcelain laminate veneers have been a viable option for restoring anterior teeth for almost three decades due to their aesthetic appeal, durability, and biocompatibility. Today, ceramic veneers are mainly used to optimize tooth form and position, close diastemas, replace unaesthetic composite resin restorations, restore teeth with incisor wear or tooth erosion and mask or reduce tooth discoloration $[12,13]$. They are a valid alternative to full-covered restorations, as they avoid aggressive tooth preparations and thus preserve the tooth structure $[14,15]$.

Dental fluorosis can be mild or severe, depending on various factors, including duration and amount of fluoride exposure, individual differences, weight, age, degree of physical activity, nutritional factors, and bone growth [16]. The mild form of fluorosis may appear as small, unnoticeable white streaks. In moderate-to-severe fluorosis, brownish discoloration can be seen with pitting and abrasion on the enamel surface due to poor mineralization of the enamel $[17,18]$. Therapeutic management of dental fluorosis depends on the severity of the condition. In severe cases, the use of the Thylstrup and Fejerskov Index (TFI), which characterizes changes in the enamel surface, should be considered while determining the type of treatment. The severity of fluorosis was classified with the Thylstrup and Fejerskov index (TFI) based on biological changes in the tooth enamel surface. The severity was considered to be mild when TFI $=1-3$, moderate with TFI $=4-5$ and severe with TFI $>6$ [19]. The present retrospective study evaluated the clinical quality, success rate, and estimated survival of porcelain laminate veneers in teeth with anterior fluorosis. The study's null hypothesis is that in the long term, such as ten years, anterior porcelain ceramic laminates on fluorized teeth will show low success and survival rate.

\section{Methods}

\section{Inclusion criteria of patients}

Inclusion criteria were as follows: all subjects were at least 18 years of age, able to read and sign the informed consent form, physically and psychologically able to tolerate conventional restorative procedures, free of active periodontal or pulpal disease, with existing resin restorations in good condition, and were willing to undergo follow-up examinations as indicated by investigators. Patients with a history of parafunctional habits were excluded from the study. Each patient was also informed of alternative treatment options.

Existing composite restorations, visible caries, pitting, or marginal staining were removed prior to the preparation of the tooth.

\section{Clinical examination}

Thirty-four patients (20 women, 14 men; mean age 49.7 years, range: $19-60$ years) who were treated in our clinic between March 2011 and December 2011, needed ceramic veneer restorations and met the inclusion criteria, were included in this study. All patients were given an informed consent form approved by the institutional review ethics committee of our university (ABR number: 72867572-050.01.04-55786). For all of the teeth included in the current study, the TFI was moderate (TFI: 4-5).

Three hundred fifty-eight porcelain laminate veneers (254 in the anterior maxilla and 104 in the mandible) were "functional" restorations that covered the incisal edge and part of the palatal/lingual side of the tooth with a $1 \mathrm{~mm}$ high palatal bevel. Among the anterior maxillary restorations, 68 were carried out on the central incisors, 68 on the lateral incisors, 58 on the canines, and 60 on the premolars. In the mandible, 26 crowns were located on the central incisors, 26 on the lateral incisors, 26 on the canines, and 26 on the premolars (Table 1).

\section{Pre-treatment procedures}

Prior to treatment with ceramic veneers, gingival corrections, teeth whitening procedures, and orthodontic alignment arrangements were carried out as necessary. Aesthetic evaluations were carried out on plaster models and digital photographs taken in the articulator using face-bow recordings. The color was determined under standard conditions in the dental laboratory. Wax modeling was carried out on the plaster model using the mockup technique and was necessary to communicate details on correcting the form and position of the teeth with the patient and the technician and evaluating the patient's

Table 1 The restorations carried out relative to the location of the teeth

\begin{tabular}{llllll}
\hline & $\begin{array}{l}\text { Central } \\
\text { incisors }\end{array}$ & $\begin{array}{l}\text { Lateral } \\
\text { incisors }\end{array}$ & Canine & Premolar & $\begin{array}{l}\text { Total number } \\
\text { of ceramic } \\
\text { veneers }\end{array}$ \\
\hline $\begin{array}{l}\text { Maxillary arch } \\
\text { ven }\end{array}$ & 68 & 58 & 60 & 254 \\
$\begin{array}{l}\text { Mandibular } \\
\text { arch }\end{array}$ & 26 & 26 & 26 & 26 & 104 \\
$\begin{array}{l}\text { Total number } \\
\text { of ceramic } \\
\text { veneers }\end{array}$ & 94 & 94 & 84 & 88 & 358 \\
\hline
\end{tabular}


expectations. After obtaining approval of the mock-up from the patient, dental preparations were initiated.

\section{Tooth preparation}

Surface preparation for the rehabilitation of teeth with moderate fluorosis using ceramic veneers are well established general procedures. In this context, the cut was kept minimal, and restricted to the enamel surface as much as possible. It has been shown in the literature that window-type labial enamel preparation should be avoided; incisal bevel preparation is preferred instead. To prepare the tooth, three horizontal surface depths of $0.3 \mathrm{~mm}$ at the enamel-cementum junction, $0.5 \mathrm{~mm}$ at the middle third, and $0.7 \mathrm{~mm}$ at the incisal third were used for a depth-limiting bur. Depth grooves were marked with a pencil. A retraction cord (Ultrapak Cord \#00, Ultradent Products Inc., South Jordan, UT, USA) was placed for protecting the gingival tissue. The cutting edge was reduced by $1.5 \mathrm{~mm}$ with a diamond bur to create a distinctive chamfer finish line continuous with the facialproximal outline. The preparation was more extensive due to brown staining on the mesial and distal proximal surfaces while the cervical margin was at the gingival level (Fig. 1). After the incisal edge angles were rounded, the exposed dentin areas were determined, and immediately closed with a universal adhesive. Following this, the final preparation and occlusion were evaluated.

\section{Final impressions and temporary restorations}

Impressions were taken with a polyvinylsiloxane material (Virtual, Ivoclar Vivadent, Amherst, NY) according to the manufacturers instructions. The labial surface of each prepared tooth was spot etched with 37\% phosphoric acid (Self Etch, Kuraray Dental, Japan) and a bonding agent (Clearfil SE Bond, Kuraray Dental, Japan) was applied to these spots. A high-intensity light-emitting diode (LED) light was applied for $20 \mathrm{~s}$ (Elipar S10, $3 \mathrm{M}$ ESPE, MN, USA). A prefabricated transparent matrix (3 M ESPE, MN, USA) was loaded with a temporary resin material and placed on the tooth. Light curing was applied for $10 \mathrm{~s}$ to each tooth.

\section{Adhesive cementation}

Ceramic veneers were fabricated with lithium disilicate reinforced glass-ceramic material (IPS e.max Press, Ivoclar Vivadent, Schaan, Liechtenstein). Temporary veneers were removed, and the teeth were cleaned using polishing paste and prophylaxis brushes. A clear trial resin (Variolink Veneer try-in paste, Ivoclar Vivadent, Schaan, Liechtenstein) was used to assess marginal adaptation and color of the veneers. Next, the inner surface of the restoration was prepared for cementation. After etching with hydrofluoric acid (Ceramic Etchant 9.5\%, Bisco Inc., Schaumburg, IL, USA) for $60 \mathrm{~s}$, the area was washed with pressurized water for the same duration as the acid etching and dried with an air-water spray. Silane (Clearfil SE Bond KIT, Kuraray Dental, Japan) was applied for $60 \mathrm{~s}$ to the inner surface that would come in contact with the tooth, followed by a short duration of air drying. A layer of bonding agent (Clearfil SE Bond KIT, Kuraray Dental, Japan) was applied to the prepared tooth surfaces and thinned with air. Following this, Heliobond (Ivoclar Vivadent, Schaan, Liechtenstein) was placed on the prepared tooth surfaces. The inner surface was coated with light-cured resin cement (Variolink Veneer, transparent shade, Ivoclar Vivadent, Schaan, Liechtenstein). Veneers were appropriately placed on the tooth by applying gentle

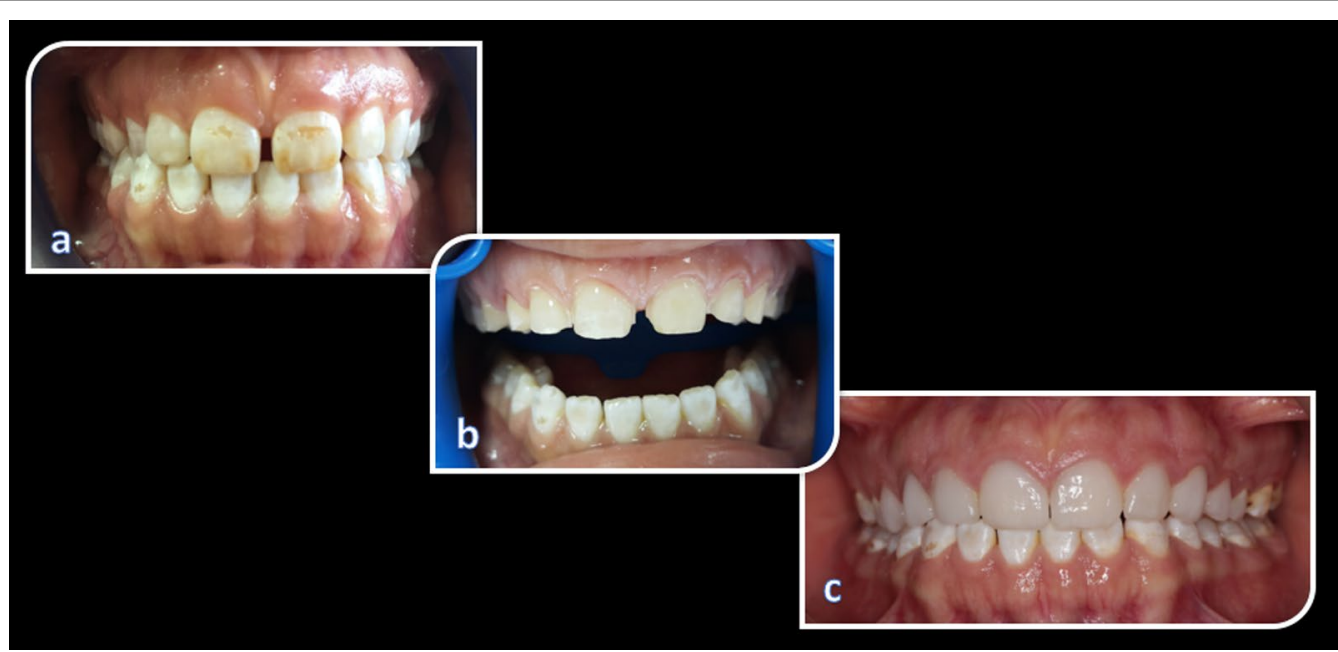

Fig. 1 a before, $\mathbf{b}$ preperation, $\mathbf{c}$ after 
pressure. Next, light was applied on each laminate veneer from the facial and lingual regions for $40 \mathrm{~s}$.

\section{Evaluation}

The modified United States Public Health Service criteria were used for clinical evaluation of the restorations. On the basis of these criteria, marginal adaptation, color match, marginal discoloration, surface roughness, restoration fracture, tooth fracture, restoration wear, antagonist tooth wear, caries and postoperative sensitivity were evaluated yearly (Fig. 2).

\section{Statistical analyses}

A descriptive approach was adopted for statistical analysis. Descriptive statistics are presented as numbers and percentages. A sample size of 3960 achieves $100 \%$ power to detect an effect size (W) of 0.1129 using a 19 degrees of freedom Chi-Square Test with a significance level (alpha) of 0.05000 . The Kaplan Meier method was used to analyze the survival rates of ceramic laminates. Survival time was defined as the time from cementation to failure of the restoration. The main criterion used to define the failure of the veneer was fracture of the ceramic and/or deterioration of adhesion [20].
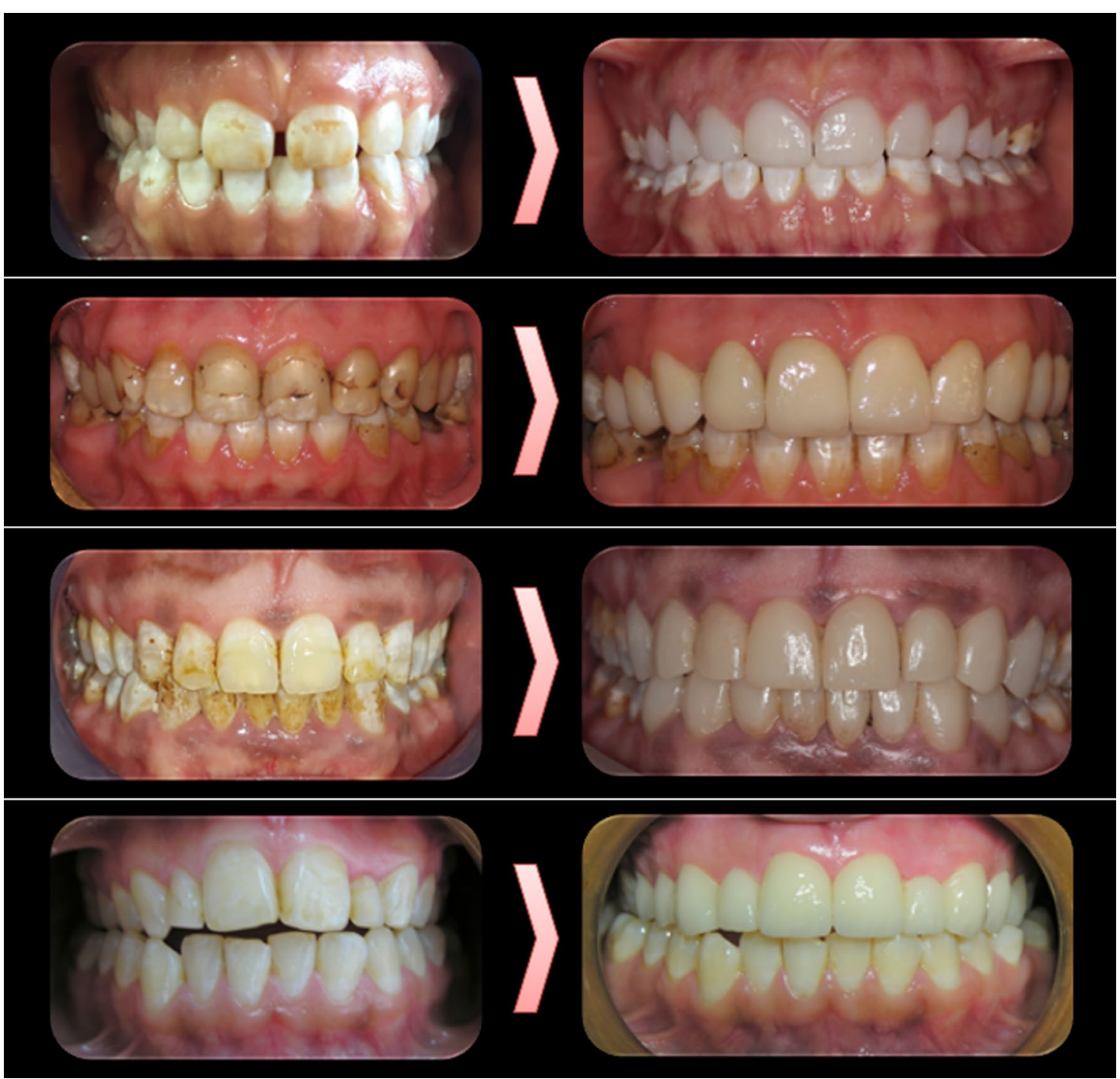

Fig. 2 Before-after photos in 10-year follow-up results 


\section{Results}

The findings observed during the follow-up period for the teeth numbered 45, 35, 15, 14 are shown in Table 2.

- According to Table 2, the survival rate in the current study was $\geq 0.997$.

- Retention of the veneer ReBonded was observed in teeth 34 and 45 at the 12th month follow-up, while small acceptable fractures were detected in tooth 35 at the 24th-month follow-up.

- At the 48th month follow-up, the veneer ReBonded and retention of the secondary caries Bravo was observed in teeth 15 and 14 .

- At the 84th month follow-up, secondary caries Bravo, large cracks, Retention of the veneer Lost were detected in tooth 35 .

- At the 96th month follow-up, large cracks, widespread fractures and Retention of the veneer Lost were detected in tooth 45 .

- At the 108th month follow-up, retention of the veneer Lost, and large cracks were detected in tooth 45.

- Distribution of the different failures observed with the veneers (Fig. 3)

\section{Discussion}

Dental fluorosis is known as a developmental disorder of the enamel. Clinical studies evaluating the effectiveness of available techniques for the treatment of fluorosis are lacking in the literature, and long-term results have not been demonstrated. Most published studies are clinical case reports, making it difficult to compare the findings of the current study with those in the literature [21-24]. The current study aimed to evaluate the long-term outcome of treatment approaches with ceramic veneers in patients with dental fluorosis. Based on the findings of this clinical trial, our null hypothesis was rejected.

Dental fluorosis affects primarily those individuals who live in areas with excessive fluoride in their drinking water. It is defined as developmental disorder of the tooth enamel due to excessive fluoride exposure, and is usually manifested in pediatric patients [25]. During tooth development, a high fluoride concentration can particularly affect cells called ameloblasts that are responsible for enamel formation [26]. Interactions between the mineral matrix of the developing enamel and ameloblasts lead to the changes observed in the enamel. Increased fluoride intake during enamel mineralization is accompanied by a decrease in free calcium ion concentration in the mineralizing matrix, which prevents enzyme proteases from breaking down matrix proteins during the maturation phase [27-30]. Therefore, the degradation of matrix proteins is delayed [27]. In addition, the presence of fluoride-induced retention of enamel matrix proteins such as amelogenins, ameloblastins, tuftelins, enamelin, and high molecular weight sulfated proteins leads to impaired crystal growth [18, 27].

The classification criteria established by Thylstrup and Fejerskov can be used to determine treatment modalities based on the biological aspects of dental fluorosis [10]. Bleaching and enamel microabrasion are non-invasive

Table 2 Descriptive statistics and estimated survival rate for the variables studied

\begin{tabular}{|c|c|c|c|c|c|}
\hline & $\begin{array}{l}\text { Number of } \\
\text { healthy teeth }\end{array}$ & $\begin{array}{l}\text { Number of } \\
\text { falling teeth }\end{array}$ & Tooth number & Time (months) & $\begin{array}{l}\text { Estimate of cumulative } \\
\text { proportion of survival }\end{array}$ \\
\hline \multirow[t]{3}{*}{ Secondary caries Bravo } & \multirow[t]{3}{*}{$3957(99.92)$} & \multirow[t]{3}{*}{$3(0.08)$} & 15 & 48 & \multirow[t]{2}{*}{0.999} \\
\hline & & & 14 & 48 & \\
\hline & & & 35 & 84 & 0.999 \\
\hline Crack Small acceptable & $3959(99.97)$ & $1(0.03)$ & 35 & 24 & 1.000 \\
\hline \multirow[t]{3}{*}{ Crack Large } & \multirow[t]{3}{*}{$3957(99.92)$} & \multirow[t]{3}{*}{$3(0.08)$} & 35 & 84 & 0.999 \\
\hline & & & 45 & 96 & 0.998 \\
\hline & & & 45 & 108 & 0.997 \\
\hline Fracture Extensive & $3959(99.97)$ & $1(0.03)$ & 45 & 96 & 0.999 \\
\hline \multirow[t]{5}{*}{ Retention of the veneer ReBonded } & \multirow[t]{5}{*}{$3955(99.87)$} & \multirow[t]{5}{*}{$5(0.13)$} & 34 & 12 & \multirow[t]{3}{*}{0.999} \\
\hline & & & 45 & 12 & \\
\hline & & & 45 & 12 & \\
\hline & & & 15 & 48 & 0.998 \\
\hline & & & 14 & 48 & \\
\hline \multirow[t]{3}{*}{ Retention of the veneer lost } & \multirow[t]{3}{*}{$3957(99.92)$} & \multirow[t]{3}{*}{$3(0.08)$} & 35 & 84 & 0.999 \\
\hline & & & 45 & 96 & 0.998 \\
\hline & & & 45 & 108 & 0.997 \\
\hline
\end{tabular}




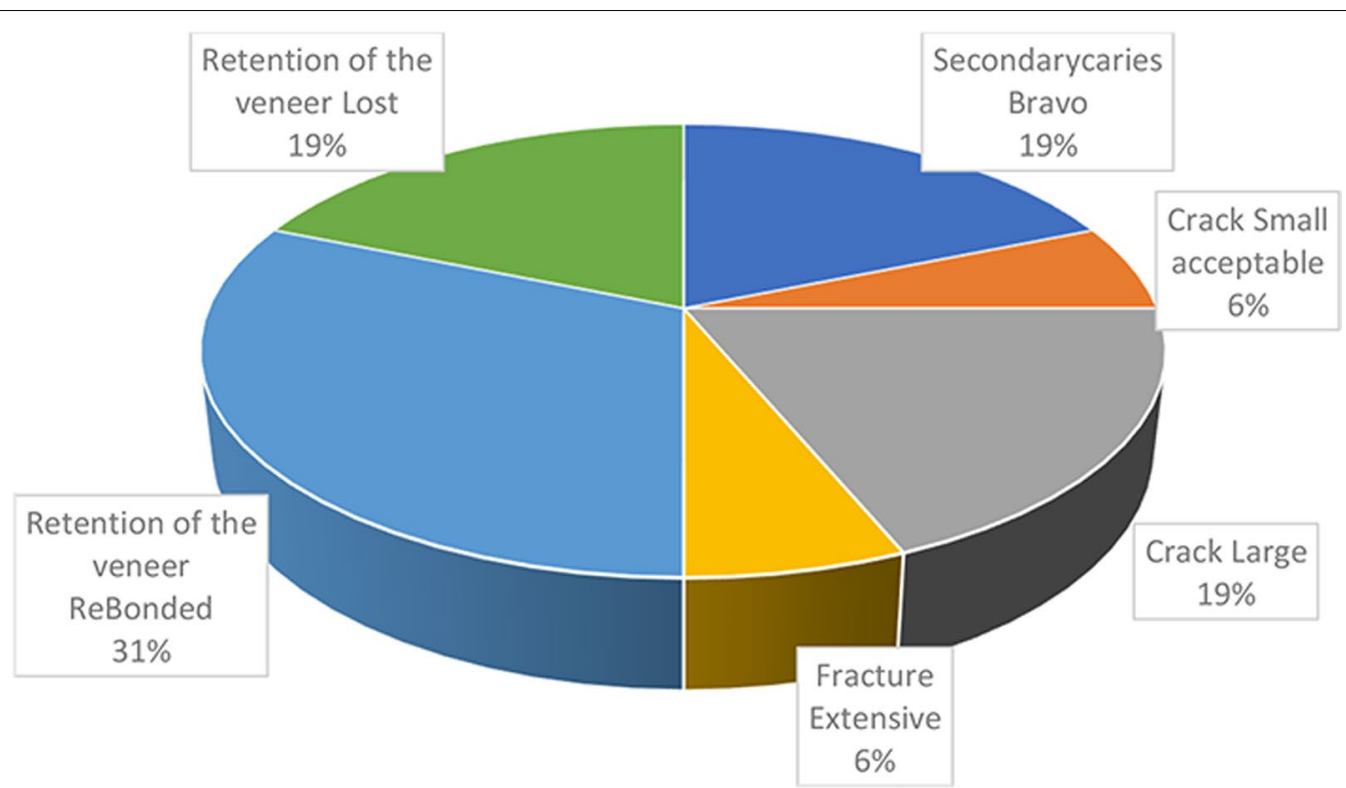

Fig. 3 Distrubution of the different failures observed with the laminate veneers

procedures that are recommended for cases with mild to moderate fluorosis with a TFI score of 0-4 [31]. Based on recommendations by Akpata, mild fluorosis with a TFI score of 1-2 can be treated with bleaching [32]. Bleaching agents can ameliorate external stains in cases where the porosity is superficial [33]. Subsurface porosity is known to be deep in cases with TFI scores of 3-4; in such cases, bleaching alone is unlikely to be effective. Thus, a combination of bleaching with microabrasion can be used in such cases to remove fluorosis stains. The porous enamel region is located approximately $80-100 \mu \mathrm{m}$ below the surface enamel in teeth with a TFI score of 1-3. Since micro-abrasion causes an approximately $100 \mu \mathrm{m}$ loss of surface enamel it should be recommended for the treatment of mild fluorosis. Teeth with a TFI score of 5-7 should be treated with ceramic veneers, while teeth with a TFI score of 8-9 should be crowned because more than $50 \%$ of the enamel is lost $[32,33]$.

Treatment options for dental fluorosis include micro/ macro etching, bleaching, composite restorations, veneers, and full crowns. Other conservative techniques for treating dental fluorosis include composite veneers, resin infiltration, and tooth jewelry. Since dental fluorosis is an endemic public health problem, availability of such treatment options can provide better outcomes in patients [10,34]. However, no randomized controlled trials have been conducted to date to evaluate treatment approaches such as crowns and ceramic veneers. Based on the classification criteria of Thylstrup and Fejerskov, ceramic veneers were chosen as the best treatment option to mask tooth discoloration in dental fluorosis patients in the current study [10, 35]. As with any technique in development, the use of ceramic coatings requires both medium-term and long-term studies to confirm their usefulness and ensure their continued use [20]. The treatment protocols used in the current study were aimed to improve the smile of the patient and provide aesthetic rehabilitation of the teeth. This aim was achieved by using ceramic veneers, which is the treatment of choice to mask tooth discoloration in cases with moderate fluorosis. Because ceramic veneers require a minimally invasive design, they can completely mask the discolored tooth with minimal reduction of intact tooth material, providing predictable and long-term aesthetic rehabilitation. Glass-ceramics have excellent translucency; moreover, the presence of $35 \%$ leucite crystals can reflect light and contribute to the durability of the material. The bonding mechanism of enamel is more effective compared to dentin [11]. Correct choice of ceramic material can allow stable aesthetic qualities whilst maintaining biocompatibility, abrasion resistance, good translucency, color, and contour stability. In addition, the risk of gingival irritation may be reduced due to lower plaque deposition around ceramic veneers compared to natural teeth [36, 37].

Magne and Douglas reported that the average local flexibility of teeth was doubled with the removal of the outer enamel, and tooth hardness was fully restored after ceramic veneer bonding. These data strongly suggest that restorations can mimic the biomechanical properties and structural integrity of the original tooth and confrm their biomimetic behavior [36, 38]. 
Ceramic veneers are primarily used for aesthetic reasons. Therefore, they can be considered to be elective rather than necessary for the maintenance of health, at least in terms of removing and restoring diseased tooth tissue. However, despite the more minimally invasive nature of its preparation when compared to a crown, the veneered tooth very often requires restorative dentistry [39]. For these reasons, the longevity of a ceramic veneer is of utmost importance. The durability and clinical success of ceramic coatings have been extensively studied in the literature. Ceramics veneers have been reported to provide durable and successful restoration with an estimated survival probability of $93.5 \%$ over ten years. Satisfactory results were obtained over a six-year follow-up period for restoration of teeth with fluorosis with ceramic crowns. In addition, numerous studies have shown acceptable aesthetic results with restorations using ceramic veneers in cases with moderate to severe fluorosis [34].

Improvements in clinical performance must address the root causes of failure. The leading causes of failure observed in clinical trials are still secondary caries in the tooth and fractures in the restoration. In the current study, the teeth with the highest rate of failure of restoration observed with long-term follow-up were the mandibular premolars. Thus, mandibular premolars are less resistant to occlusal loads than other teeth due to their narrower counter-occlusal layer. In addition, the widespread restoration failure in the mandibular premolar region may also have emanated from the difficulties in maintaining proper oral hygiene in this region.

\section{Conclusions}

Ceramic veneers are considered to be one of the most popular restorative materials in aesthetic dentistry. They provide excellent outcomes when an appropriate treatment plan and protocol are used during the clinical and laboratory production stages. The current study recommends the use of ceramic veneers to improve the appearance of fluorotic teeth, thereby improving the patient's smile. The results of this clinical study should encourage clinicians to consider ceramic veneers over crown restorations when restoring the smile of patients with advanced fluorosis.

\section{Abbreviation}

TFl: Thylstrup and Fejerskov Index.

\section{Acknowledgements}

The authors thank Dr. Orhan H., Department of Biostatistics and Medical Informatics, Faculty of Medicine, Suleyman Demirel Univercity, Turkey for help with the statistical analyses.

\section{Authors' contributions}

ZBD: Data curation, Formal analysis, Project administration, Resources, Writingoriginal draft, Writing-review and editing). ST: Investigation, Methodology, Project administration, Software, Writing-original draft, Writing-review and editing). Both authors read and approved the final manuscript.

Funding

The authors did not receive any funding from any organizations.

\section{Availability of data and materials}

The data that support the fndings of this study are available from the corresponding author upon reasonable request.

\section{Declarations}

\section{Ethics approval and consent to participate}

The ethical conduct of this study was approved by the School of Medicine Ethics Committee, Süleyman Demirel University (72867572-050.01.04-55786). The participants signed a written informed consent form following the Helsinki Declaration of the World Medical Association.

\section{Competing interests}

The authors declare no confict of interest with respect to the authorship and/ or publication of this article.

Received: 9 December 2021 Accepted: 9 February 2022

Published online: 17 February 2022

\section{References}

1. Kleiman K. Try some smile therapy. Psychology Today. 2012; 31 July, viewed 25 October 2013.

2. Garber DA, Salama MA. The aesthetic smile: diagnosis and treatment. Periodontol. 1996;2000(11):18-28.

3. Messer LB, Mekertichia K. Fluorid modalities. In: Cameron AC, editor. R Widmer: handbook of pediatric dentistry. Mosby: Elsevier; 2008. p. 53-7.

4. Abanto Alvarez J, Rezende KM, Marocho SM, Alves FB, Celiberti P, Ciamponi AL. Dental fluorosis: exposure, prevention and management. Med Oral Patol Oral Cir Bucal. 2009;14(2):E103-7.

5. Browne D, Whelton H, O'Mullane D. Fluoride metabolism and fluorosis. J Dent. 2005;33(3):177-86.

6. Bartlett JD, Dwyer SE, Beniash E, Skobe Z, Payne-Ferreira TL. Fluorosis: a new model and new insights. J Dent Res. 2005:84(9):832-6.

7. Al-Sugair MH, Akpata ES. Effect of fluorosis on etching of human enamel. J Oral Rehabil. 1999;26(6):521-8.

8. Romero MF, Babb CS, Delash J, Brackett WW. Minimally invasive esthetic improvement in a patient with dental fluorosis by using microabrasion and bleaching: a clinical report. J Prosthet Dent. 2018;120(3):323-6.

9. Kulkarni RS, Pimpale SK, Powar SN. Interdisciplinary approach to complete-mouth rehabilitation: a clinical report. Gen Dent. 2016;64(6):e10-5.

10. Dogui H, Dakhli R, Abdelmalek F, Nouira Z, Amor A, Cherif M. Aesthetic rehabilitation of severe dental fluorosis with porcelain veneers: about a case report. J Dent and Med Sci. 2019;18(11):57-63.

11. Shah N, Jain K, Khanna A, Badwaik P, Pai A, Jambhekar S, Gharat N. Esthetic full mouth rehabilitation to correct fluorosis defects: a complete digital workflow. World J Adv Sci Res. 2019;2(3):137-44.

12. Garber DA, Goldstein RE, Feinman RA. Porcelain laminate veneers. Chicago: Quintessence; 1988.

13. Friedman MJ. Porcelain veneer restorations: a clinician's opinion about a disturbing trend. J Esthet Restor Dent. 2001;13(5):318-27.

14. Fradeani M. Six-year follow-up with Empress veneers. Int J Periodontics Restorative Dent. 1998;18(3):216-25.

15. Beier US, Kapferer I, Burtscher D, Dumfahrt H. Clinical performance of porcelain laminate veneers for up to 20 years. Int J Prosthodont. 2012;25(1):79-85

16. Black GV. Mottled teeth: an endemic developmental imperfection of the enamel of the teeth heretofore unknown in the literature of dentistry. Dental Cosmos. 1916;58:129-56. 
17. Shafiei F, Tavangar M, Alavi A. Direct esthetic rehabilitation of teeth with severe fluorosis: a case report. J Dent (Shiraz). 2014;15(1):44-7.

18. Shahroom NSB, Mani G, Ramakrishnan M. Interventions in management of dental fluorosis, an endemic disease: a systematic review. J Family Med Prim Care. 2019;8(10):3108-13.

19. Sarkar I, Gupta AB, Gupta SK. Human health effects of drinking water fluoride contamination: Indian Scenario. In: 15th international conference on environmental science and technology rhodes, Greece, 31 August-2 September 2017

20. Granell-Ruiz M, Fons-Font A, Labaig-Rueda C, Martínez-González A, Román-Rodríguez JL, Solá-Ruiz MF. A clinical longitudinal study 323 porcelain laminate veneers Period of study from 3 to 11 years. Med Oral Patol Oral Cir Bucal. 2010;15(3):e531-7.

21. Pontes DG, Correa KM, Cohen-Carneiro F. Re-establishing esthetics of fluorosis-stained teeth using enamel microabrasion and dental bleaching techniques. Eur J Esthet Dent. 2012;7(2):130-7.

22. Bertassoni LE, Martin JM, Torno V, Vieira S, Rached RN, Mazur RF. In-office dental bleaching and enamel microabrasion for fluorosis treatment. J Clin Pediatr Dent. 2008;32(3):185-7.

23. Higashi C, Dall'Agnol AL, Hirata R, Loguercio AD, Reis A. Association of enamel microabrasion and bleaching: a case report. Gen Dent. 2008;56(3):244-9.

24. Castro KS, Ferreira AC, Duarte RM, Sampaio FC, Meireles SS. Acceptability, efficacy and safety of two treatment protocols for dental fluorosis: a randomized clinical trial. J Dent. 2014;42(8):938-44.

25. Gupta A, Dhingra R, Chaudhuri P, Gupta A. A comparison of various minimally invasive techniques for the removal of dental fluorosis stains in children. J Indian Soc Pedod Prev Dent. 2017;35(3):260-8.

26. $\mathrm{Ng} \mathrm{F}$, Manton DJ. Aesthetic management of severely fluorosed incisors in an adolescent female. Aust Dent J. 2007;52(3):243-8.

27. Aoba T, Fejerskov O. Dental fluorosis: chemistry and biology. Crit Rev Oral Biol Med. 2002;13(2):155-70.

28. Wright JT, Chen SC, Hall KI, Yamauchi M, Bawden JW. Protein characterization of fluorosed human enamel. J Dent Res. 1996;75(12):1936-41.

29. DenBesten PK. Biological mechanisms of dental fluorosis relevant to the use of fluoride supplements. Community Dent Oral Epidemiol. 1999;27(1):41-7.

30. Robinson C, Connell S, Kirkham J, Brookes SJ, Shore RC, Smith AM. The effect of fluoride on the developing tooth. Caries Res. 2004;38(3):268-76.

31. Thylstrup A, Fejerskov O. Clinical appearance of dental fluorosis in permanent teeth in relation to histologic changes. Community Dent Oral Epidemiol. 1978;6(6):315-28

32. Akpata ES. Occurrence and management of dental fluorosis. Int Dent J. 2001;51(5):325-33.

33. Akpata ES. Therapeutic management of dental fluorosis: a critical review of literature. Saudi J Oral Sci. 2014;1 (1):3.

34. El Mourad AM. Aesthetic rehabilitation of a severe dental fluorosis case with ceramic veneers: a step-by-step guide. Case Rep Dent. 2018;6(2018):4063165

35. Sherwood IA. Fluorosis varied treatment options. J Conserv Dent. 2010;13(1):47-53

36. Fradeani M, Redemagni M, Corrado M. Porcelain laminate veneers: 6to 12-year clinical evaluation-a retrospective study. Int J Periodontics Restorative Dent. 2005;25(1):9-17.

37. Magne P, Kwon KR, Belser UC, Hodges JS, Douglas WH. Crack propensity of porcelain laminate veneers: a simulated operatory evaluation. J Prosthet Dent. 1999:81(3):327-34.

38. Magne P, Douglas WH. Porcelain veneers: dentin bonding optimization and biomimetic recovery of the crown. Int J Prosthodont. 1999;12(2):111-21.

39. Burke FJ, Lucarotti PS. Ten-year outcome of porcelain laminate veneers placed within the general dental services in England and Wales. J Dent. 2009;37(1):31-8.

\section{Publisher's Note}

Springer Nature remains neutral with regard to jurisdictional claims in published maps and institutional affiliations.

Ready to submit your research? Choose BMC and benefit from:

- fast, convenient online submission

- thorough peer review by experienced researchers in your field

- rapid publication on acceptance

- support for research data, including large and complex data types

- gold Open Access which fosters wider collaboration and increased citations

- maximum visibility for your research: over $100 \mathrm{M}$ website views per year

At BMC, research is always in progress.

Learn more biomedcentral.com/submissions 